\title{
IT und Recht
}

Die Größe eines Wortes stellt die relative Häufigkeit in den Beiträgen des Heft-Schwerpunktes dar.

\section{IT-Grundschutzkataloge \\ Grundlage}

Bausteine Digitalisierung

Zugang Deutschland Angreifer

legal Kunden Analyse

Sicherheit WAN Anwaltschaft
Informationen DSGVO digitale

. DIN IT Sicherheitsvorfälle

Unternehmen ${ }^{\text {Betrieb }}$

UDaten.

일

Daten $\mathrm{BSI}$

Mitarbeiter

Datensicherheit

Verbraucher

Zertifizierung : 